\title{
Asistir a la cita de la posdictadura. Historicidad, performance y políticas del cuerpo entre Emilio García Wehbi y el Periférico de Objetos
}

\section{Assist to the Call of Postdictatorship. Historicity, Performance and Politics of the Body between Emilio García Wehbi and the Periférico de Objetos}

Artículo recibido el Io de noviembre de 20I6; devuelto para revisión el I8 de enero de 20I7; aceptado el 4 de septiembre de 20I7, http://dx.doi.org/IO.2220I/iie.I8703062e.20I8.II2.2625
Francisco Gelman Consejo Nacional de Investigaciones Científicas y Técnicas/Univer- Constantin sidad de Buenos Aires-Instituto de Literatura Hispanoamericana, Argentina.simbiosisficticia@hotmail.com

Líneas de investigación Literatura y artes escénicas latinoamericanas de los siglos xx y xxI; objeto literario y biomedicina; cuerpo y culturas corporales; psicoanálisis y feminismo psicoanalítico; teoría literaria; temporalidades del arte y la escritura.

Lines of research Latin-American literature and scenic arts from the 2oth and 2ist centuries; literary object and biomedicine; body and bodily cultures; psychoanalysis and psychoanalytic feminism; literary theory; timeliness of the arts and writing.

Publicaciones más relevantes

"La naturaleza y los faunos. Ercole Lissardi hacia la monstruosidad del deseo", en Nora Domínguez, Elizabeth Caballero del Sastre, Ana Laura Martín, Valeria Pita, Elsa Rodríguez Cidre, María Laura Rosa, Alicia Schniebs y Marcela Suárez, comps, Figuras y saberes de lo monstruoso (Universidad de Buenos Aires-Facultad de Filosofía y Letras, 2016): 205-215; "58 indicios, metáforas, montajes. La obra heterogénea en los estudios literarios latinoamericanos actuales", Estudios de Teoría Literaria, núm. I2 (2017): I5I-I62; "Barajar y dar con Bestiario: la vida y sus formas cortazarianas", Cuadernos del Sur-Letras, núm. 46 (2017): 85-96; "Lo trágico de un paso. Cuerpo acrobático y duelo en la escena circense contemporánea”, telondefondo.org, núm. 23 (2016): 47-6I; "Hay lugar para los débiles. Configuraciones de la violencia en el Chaco argentino: género negro, subjetividades y espacio", Revista Chilena de Literatura, núm. 90 (2015): I05-128; "Un episodio del pensamiento francés de la autonomía. Benjamin Constant y las idées très ingénieuses", Lingue e Linguaggi, vol. Io (2013): 47-62. 
Resumen En diálogo con la reivindicación teórica contemporánea del anacronismo como antídoto contra el historicismo positivista, el artículo explora la obra performática y teatral de Emilio García Wehbi en sus relaciones con la producción del Periférico de Objetos, con la expectativa de investigar qué implica la incorporación del cuerpo escénico en una concepción compleja y fracturada de la temporalidad del arte. En la instauración de la posdictadura como un efecto retroactivo de producción de historicidad a lo largo del tiempo escindido de la obra, la desincronización aparece como un acto político de desafío a las biopolíticas de Estado. La suscitación de una teoría sobre las relaciones entre lenguaje y cuerpo adecuada a este decir escénico permite además recorrer algunas disputas conceptuales actuales y defender una concepción del montaje como modo de comprender la articulación de tiempos, cuerpos y sujetos en su heterogeneidad.

Palabras clave Anacronismo; historicidad; cuerpo; performance; montaje; psicoanálisis.

Abstract In dialogue with the contemporary theoretical vindication of anachronism as an antidote for positivist historicism, this paper explores Emilio García Wehbi’s performance and theatrical pieces; their relationship with the production of his former group Periférico de Objetos, in order to study the implications of incorporating the scenic body into a complex and fractured conception of art's temporality.

As "post-dictatorship" becomes established as a retroactive effect of the production of historicity through the split time of the work, desynchronization appears as a political act challenging State biopolitics. The creation of a theory on the relationship between language and the body best suited for this scenic outcome allows us also to address some current notional struggles and to advocate a concept of montage as a way towards understanding how different times, bodies and subjects are articulated, notwithstanding their heterogeneousness.

Keywords Anachronism; historicity; the body; performance; montage; psychoanalysis. 
DOI: http://dx.doi.org/10.22201/iie.18703062e.2018.112.2625

FRANCISCO GELMAN CONSTANTIN

CONSEJO NACIONAL DE INVESTIGACIONES CIENTÍFICAS Y TÉCNICAS/

UNIVERSIDAD DE BUENOS AIRES

INSTITUTO DE LITERATURA HISPANOAMERICANA

ARGENTINA

\title{
Asistir a la cita de la posdictadura Historicidad, performance $y$ politicas del cuerpo entre Emilio García Wehbi y el Periférico de Objetos
}

\begin{abstract}
¿Acaso no nos roza a nosotros mismos una brisa del aire que rondaba a los de antes? ¿no hay en las voces a las que prestamos nuestro oído un eco de las que ahora enmudecieron? ¿no tienen las mujeres a las que galanteamos hermanas que ya no han conocido? De ser así, entonces hay una cita secreta entre las generaciones pasadas y la nuestra. Entonces se nos ha esperado en la Tierra.

Walter Benjamin, “Über den Begriff der Geschichte”, I940

Para Benjamin el poder de las citas no nace de su capacidad de transmitir y hacer revivir el pasado, sino por el contrario, de su capacidad de hacer limpieza de todo, de extraer del contexto, de destruir.
\end{abstract}

Giorgio Agamben, El hombre sin contenido, 1970

\footnotetext{
7 elebración, soberanía, libertad, orgullo, potencia. Con algunas de estas palabras festejan las reseñas periodísticas la emancipación experimentada por los cuerpos de los y las performers que pronuncian textos, se desnudan y danzan alrededor de sus despojos de vestimenta a lo largo de las tres horas que dura 58 indicios sobre el cuerpo, en las cinco funciones que alojó el teatro
} 
DOI: http://dx.doi.org/10.22201/iie.18703062e.2018.112.2625

I2

FRANCISCO GELMAN CONSTANTIN

Timbre 4 de Buenos Aires durante julio y agosto de 20I4, y la función suplementaria en el Centro Cultural de la Memoria Haroldo Conti en noviembre de ese mismo año. ${ }^{\mathrm{I}}$ Fácilmente —y con justicia— se puede compartir el entusiasmo de esas publicaciones. Vale la pena, con todo, añadir a ello un detalle que muchas de ellas pasan por alto, pero que pudo saltar a la vista de cualquier espectador: la presencia, entre tanta algarabía, de un cuadrado de tierra seca. El cuadrado de tierra seca enmarca el performance desde antes de que entren en la sala espectadores y artistas, en visible contrapunto con el barro con el que los y las intérpretes pintan más adelante sus cuerpos. Ese rectángulo de tierra persiste como mancha en el panorama visual del performance, su trazado no es perturbado por ninguno de los movimientos y, para quien conozca la trayectoria de Emilio García Wehbi, autor y director del performance, es difícil no reconocer en él la tierra de la que emergen y en la que vuelven a sumergirse los muñecos de El hombre de arena, obra en la que había participado en 1992 como integrante de la compañía Periférico de Objetos. Como si para que los cuerpos de 58 indicios pudieran emanciparse sobre escena hubiera sido preciso, primero, seguirlos desenterrando.

En las investigaciones teatrales, literarias, estéticas y culturales contemporáneas — desde la gravitación decisiva de un conjunto de relecturas actuales de la obra de Aby Warburg, ${ }^{2}$ así como de estudiosos y estudiosas inspirados por las objeciones al historicismo de Walter Benjamin o Jacques Lacan-, ${ }^{3}$ el anacronismo aparece como un nodo conceptual clave para la formulación de una historia de las prácticas y los objetos materiales, que desafíe la linealidad historiográfica y los residuos de teleología en el relato del pasado. En la historia del arte, paradigmáticamente, Georges Didi-Huberman rastrea en la imagen "un montaje de tiempos heterogéneos y discontinuos que, sin embargo, se conectan y se interpenetran"; 4 de este modo concibe la noción warburguiana

I. Ivana Soto, "El lugar de las batallas", en Revista N", suplemento de Clarín, I3 de agosto de 20I4: 30; Laura Rosso, "Carne de cañón”, en "Las I2", suplemento de Página/ı2, 24 de octubre de 20I4: 4.

2. Georges Didi-Huberman, Ante el tiempo, trad. Antonio Oviedo (Buenos Aires: Adriana Hidalgo, 20II) y La imagen superviviente, trad. Juan Calatrava (Madrid: Abada, 2009); Giorgio Agamben, "Aby Warburg y la ciencia sin nombre”, en La potencia del pensamiento, trad. Flavia Costa y Edgardo Castro (Buenos Aires: Adriana Hidalgo, 2007), I57-187; Daniel Link, Fantasmas: imaginación y sociedad (Buenos Aires: Eterna Cadencia, 2009).

3. Joan Copjec, Read My Desire. Lacan Against the Historicists (Cambridge: MIT, 1994) e Imagine Therés No Woman (Cambridge, Mass: MIT, 2002); Graciela Speranza, Atlas portátil de América Latina (Buenos Aires: Anagrama, 2012); Michael Löwy, Walter Benjamin: aviso de incendio, trad. Wanda Nogueira Caldeira Brant (San Pablo: Boitempo, 2005).

4. Antonio Oviedo, "Nota preliminar", en Didi-Huberman, Ante el tiempo, ir. 
de "supervivencia" [Nachleben] en diálogo con la "imagen dialéctica" de Benjamin y la "repetición" freudiana, convergencia que transforma en punto fundamental de sus trabajos. De manera paralela, los conceptos psicoanalíticos de repetición y retorno desembarcan en el pensamiento estético, complejizan la dimensión temporal de símbolos, actos y formas, y convierten la lógica del inconsciente en umbral irrebasable para la comprensión del dinamismo de la cultura. ${ }^{5}$

La hipótesis de la retroacción temporal suscitada por un detalle en el performance de García Wehbi 2014 es el punto de partida de este trabajo, que busca comprender qué tipo de operaciones sobre el archivo artístico que él mismo guarda $-\mathrm{y}$ que sus publicaciones en la red social virtual Facebook ponen en circulación, actualizan y transforman- participan de su intervención sobre el cuerpo en escena. ¿Por qué sus creaciones teatrales y performativas, al transformarse año a año, recuperan sin embargo también de manera insistente su propio pasado? ¿Por qué la recurrente cita que perturba el vector de la deriva histórica? Y, por medio de la obra de Wehbi y del Periférico de Objetos, ¿qué lugar puede ocupar el performance en el giro anacrónico de la historiografía contemporánea de las artes y la literatura?, ¿de qué modo afecta la presencia del cuerpo performático una teoría de la historicidad de las prácticas estéticas y políticas?, y ¿qué inflexiones particulares introduce sobre la cuestión su inscripción en el territorio de disputas colectivas que sostiene la designación de "posdictadura" en la experiencia argentina reciente?

\section{Performar: un cuerpo y los tiempos}

La paradoja temporal parece intensificarse en la referencia genérica. Si el arteacción buscó en su inscripción en el presente efímero una vía de disidencia

5. Hal Foster, El retorno de lo real, trad. de Alfredo Brotons Muñoz (Madrid: Akal, 200I); Luciano Lutereau, “¿Una estética lacaniana? La estética de Lacan o una estética con Lacan”, Ramona, núm. 98 (2010): 20-28; Edgardo Cozarinsky, "Maricel Álvarez en escena: hipnosis y quimera”, en Maricel Álvarez, Yo tenía un alma buena (Buenos Aires: Fundación osDE, 20I5), 84.

6. Algunos empleos del pensamiento de Warburg para reflexionar acerca de la intervención de las artes sobre la historicidad de los cuerpos en relación con el terrorismo de Estado en la Argentina pueden buscarse en los últimos ensayos de José Emilio Burucúa, por ejemplo, José Emilio Burucúa y Nicolás Kwiatkowski, "Elpenor, el peregrino de Emaús y el desaparecido”, Boletín de Estética, núm. 20 (2012): 5-47. 
respecto de la reificación mercantil de las prácticas artísticas en objetos intercambiables e incluso la permanencia documental en archivos y museos, 7 la insistencia de Wehbi sobre la iterabilidad de los performances en los performances podría sobresaltar como una ironía calculada. Sin embargo, aunque el artista gusta de subvertir la burocratización de las tradiciones genéricas, ${ }^{8}$ la paradoja es menos nítida de lo que podría pensarse: la repetición de la obra pasada en la obra presente no sostiene una lógica de la conservación, sino de la incineración. Las piezas previas reaparecen para consumirse en escena y honrar sus cenizas, imposible devolverlas a la vitrina luego de empleadas; tal como ocurría con los juguetes antiguos de colección despedazados a martillazos por García Wehbi y Maricel Álvarez durante Herodes Reloaded (2015), sólo del resto se extrae materia futurible. La retroacción a las obras citadas nunca respeta su integridad histórica, contesta su fijabilidad en el archivo y obstaculiza su recomposición posterior: la supervivencia se opone a la conservación.

Cuanto más retrospectivo es el performance, menos se obliga a preservar la obra que retoma. El ejemplo decisivo fue la conferencia performática sin título de Wehbi el ir de julio de 2015 como parte del ciclo Direccionario de la Fundación Proa. En ella, el artista compartía la escena con algunos de los actores, actrices y performers que lo acompañaron en ocasiones anteriores y que acumulaban en su compañía fragmentos de obras pasadas, que en conjunto se transformaban en el enunciado retroactivo de una poética, para luego intercambiar preguntas y respuestas con el público de la conferencia. En el pequeńo espacio escénico del auditorio de Proa reaparecía la serie de los "Mataderos" (2005-2009), 58 indicios, Hécuba o el gineceo canino (2011) y Woyzeck (2006), reencarnados en cuerpos y voces; otra multitud de obras acompańaba la discusión con los espectadores en fotografías proyectadas sobre el fondo, desde los primeros performances del Periférico de Objetos (grupo del que formó parte durante toda su existencia, 1989-2005) hasta la actualidad. La repetición de ninguna de las obras reencarnadas, con todo, las preservaba intactas: cambios de orden, cambios de intérprete, omisiones, sustituciones. En una modificación decisiva, Horacio Marassi, encargado como en la puesta original de inter-

7. Sagrario Aznar Almazán, El arte de acción (Madrid: Nerea, 2000), 7-27.

8. Véase a este efecto la satirización de Marina Abramovic en Emilio García Wehbi y Gabo Ferro, "Contramanifiesto del método Abraham", en Artaud: lengua $\infty$ madre (Córdoba: DocumentA/Escénicas, 20I5); así como Fernando Chaves Espinach, "Emilio García Wehbi, un teatro con todos los sentidos", consultado el i4 de febrero de 20I6, en www.nacion.com/ocio/artes/ Emilio-Garcia-Wehbi-teatro-sentidos_o_I54264575I.html. 
pretar al interlocutor masculino de Hécuba, renuncia a la camiseta que lo identificaba en 201 r como Cronos, dios del continuo temporal y padre devorador de sus hijos, tanto como la de un sarcástico God of Happiness y la de Destino, para vestir — de entre los nombres previstos por el texto— 9 únicamente la de Chaos. La repetición de Hécuba coincide por esa vía con la destitución del orden de los tiempos y la disolución de la antinomia de las generaciones, reemplazados por un unívoco caos, es decir, la afirmación del múltiple (super) viviente del cuerpo de Hécuba emancipado de cometido histórico.

La repetición o la supervivencia del cuerpo de Hécuba —los términos no son intercambiables, pero en este caso ambos igualmente válidos- ${ }^{\mathrm{ro}}$ no debe confundirse con la repetición o supervivencia del cuerpo de Maricel Álvarez, por mucho que ella la encarne tanto en 201 i como en 20I5. Puesto que, por lo menos de la antropología de Lévi-Strauss en adelante, el cuerpo no puede ya concebirse como un sustrato sustancial sobre el que venga a sostenerse la cultura, sino como el producto de múltiples intervenciones en conflicto que lo constituyen ya siempre en el interior de una comunidad (sin la cual no podría subsistir), ningún predicado puede ser gratuito. Si hay cuerpo allí donde ha habido una condensación imaginaria, una configuración simbólica y un resto de dehiscencia ante las identificaciones propuestas por una época, ${ }^{\mathrm{II}}$ ninguna imagen suplementaria, ningún nombre que se añada puede carecer de consecuencias. Cada vez que a Maricel Álvarez le ocurre el cuerpo de Hécuba, sus órganos expulsan de sí la capacidad reproductiva, pues la heroína orquestada por García Wehbi es cruza de Hécuba y Medea: elimina a sus hijos para librarlos de la suerte trágica que les depara el mundo de los hombres. Es entonces, añade el texto, cuando Hécuba se transforma en perro: se refugia en la forma

9. Emilio García Wehbi, Botella en un mensaje (Córdoba: Alción-DocumentA/Escénicas, 20I2). Io. Como se advertirá, "repetición" y "supervivencia" son conceptos tomados respectivamente del psicoanálisis lacaniano y de la ciencia de la cultura warburgiana, y referidos en cada caso al modo en que la fijeza de lo real del sujeto resiste en el tiempo a la dominación del significante y a la reaparición transhistórica de una energía psíquica capturada en una fórmula imaginal. Si ya el volumen de Georges Didi-Huberman dedicado a la teoría de Aby Warburg dejaba advertir que teoría psicoanalítica e imagología, sin coincidir, podían bien concurrir, esa concurrencia es especialmente productiva para una teoría contemporánea de la existencia histórica del cuerpo, que debe de manera forzosa perseguirlo tanto en el registro de las imágenes, como en el de las formas simbólicas y el del troumatisme. Véase Jacques Lacan, Les Séminaires, ed. Charles Melman (París: A. L. I., 2004) y Didi-Huberman, La imagen superviviente.

II. La tríada recubre la distinción cuerpo imaginario/cuerpo simbólico/cuerpo real, véase Lacan, Les Séminaires. 
DOI: http://dx.doi.org/10.22201/iie.18703062e.2018.112.2625

I6

FRANCISCO GELMAN CONSTANTIN

canina para huir de "los preceptos morales que la civilización le impone". ${ }^{\text {I2 }}$ Llamamos "cuerpo de Hécuba" a aquello que se hurta a esa aprehensión, y es aquello que se repite en el tiempo como gesto mínimo negativo, aquello que sobrevive para reaparecer donde no se lo llama; y si en 201 se instalaba en escena para suspender el discurso reproductivo que le ordenaba un destino y un ciclo, en 2015 vuelve a convocarse para impedir además su captura por un discurso histórico: para afirmar la continuidad del impulso de retirar el cuerpo frente a cualquier historización que haga de aquella una batalla ya ganada.

\section{Archivar: cuerpo y objetos materiales}

Si los performance y las piezas teatrales de Wehbi reclaman el más actual de los pensamientos para comprender la historicidad paradójica del cuerpo es porque pronuncian dos exigencias simultáneas. Por una parte, el rechazo de cualquier sustancialismo, de cualquier encierro del cuerpo en una metafísica conservadora de la naturaleza: el cuerpo no precede a la Historia como un trascendental o como una Madre Tierra ultrajados por la contingencia de la historia humana, sino que - de los cirujanos-manipuladores de El hombre de arena a las clases de danza de La última noche de la humanidad (Periférico de Objetos, 2002), de la ortodoncia de El orin come el hierro, el agua come las piedras; o el sueño de Alicias (2007) a los cuellos ortopédicos de Artaud: lengua $\infty$ madre (2015) - es siempre el objeto de operaciones de producción e información, deformación y transformación. Pero si bien puede decirse de ese cuerpo, como dijo Hans-Thies Lehmann en su Postdramatisches Theater a propósito del "objeto visual" en el teatro de Bob Wilson, que "parece almacenar en sí tiempo", ${ }^{13}$ el que los cuerpos de Wehbi almacenan — segunda exigencia- no coincide nunca plenamente con el tiempo en el que ocurren y precisamente de ese anacronismo soportan su disidencia. Los cuerpos invitados por Wehbi

I2. Emilio García Wehbi, véase www.emiliogarciawehbi.com.ar/archivo/, consultado el to de febrero de 2016.

13. Hans-Thies Lehmann, Postdramatisches Theater (Fráncfort del Meno: Verlag der Autoren, 2005), 33I. La referencia al teatro posdramático no es gratuita, así más no fuera porque Heiner Müller es uno de sus casus belli y Wilson uno de los directores de escena memorables de "Hamletmaschine" (Nueva York, 1986). Sin embargo, Wehbi mismo ha señalado informalmente su relación con el posdrama en más de una ocasión. Siempre que la lengua de cita difiera del idioma en el que se consigna la referencia en la bibliografía, la traducción es ad hoc. 
están en condiciones de responder a su presente en clamor guerrero porque los habitan sujetos en permanente desincronización. ${ }^{\mathrm{I}}$

La coexistencia del sitio web del artista con su presencia en Facebook realiza la misma historicidad paradójica por otros medios. Si, por un lado, la sección "Archivo" de su página web parece albergar las imágenes fotográficas de los cuerpos en escena cada una en su tiempo, prolijamente ordenadas según una línea histórica ascendente que alinea en forma sucesiva los ańos de 1990 a 2015 , las publicaciones de las mismas imágenes en la red social — sin ser menos minuciosos los epígrafes que las acompañan- distorsionan la inmanencia histórica de los gestos escénicos. Cuando en mayo de 2015 la consigna "Ni una menos" concitaba intervenciones culturales diversas y manifestaciones multitudinarias a lo largo de Argentina en repudio a la sostenida ola de feminicidios, Wehbi reingresa en circulación por Facebook los registros gráficos de su performance El Matadero 6: Ciudad Juárez (Ciudad de México, 2008); los cuerpos amordazados de mujeres fotografiados entonces, sin dejar de pertenecer a aquellas asesinadas en la frontera mexicana, sobreviven también a su tiempo para responder a un discurso misógino panlatinoamericano poco dispuesto a retroceder su plaza. ${ }^{15} \mathrm{Si}$ en el performance de 2008 se advertía ya la impropia espacialización de los cuerpos característica de los procesos de duelo (están donde de hecho faltan, faltan donde estaban), ${ }^{16}$ el artista apoyándose en la evanescente historicidad del medio, reinstala esas imágenes corporales fuera del tiempo que fue suyo y las levanta contra la violencia machista del momento, al desnudar una persistente ubicuidad.

I4. Respecto de la desincronización o síncopa como tiempo fundante del sujeto en el sentido lacaniano (es decir como contestación del discurso de mando), puede buscarse una argumentación más detallada en Francisco Gelman Constantin, "Tiempos y sujetos para unos estudios literarios" (ponencia presentada en las VI Jornadas de Jóvenes Investigadores en Literatura y Artes Comparadas [Universidad Nacional de Tres de Febrero], Buenos Aires, del 30 de noviembre al 2 de diciembre de 20I5). Allí quedaba también apuntada al pasar la tarea pendiente, que aquí retomo en lo que sigue, de recuperar el goce no totalmente fálico como operador de disidencia temporal.

I5. Emilio García Wehbi, publicación del 24 de mayo de 2015, www.facebook.com/ GarciaWehbi?fref=nf, consultado el to de agosto de 2015 .

I6. Véase Ileana Diéguez Caballero, Cuerpos sin duelo. Iconografías y teatralidades del dolor (Córdoba: DocumentA/Escénicas, 20I3); así como la expresión "presencia de la ausencia" en Ana Longoni, Fernando Davis, Fernanda Carvajal, Daniela Lucena, Cora Gamarnik, Malena La Rocca y Gisela Laboureau, transcripción del seminario "Perder la forma humana", www.ciacentro.org.ar/sites/default/files/perder_la_forma_humana_completo_corregido.pdf, consultado el II de noviembre de 20I5; y "Enunciar la ausencia”, en Red de Conceptualismos del Sur, Perder la forma humana. Una imagen sísmica de los años ochenta en América Latina, $2^{\mathrm{a}}$. ed. (Sáenz Peña: Universidad Nacional de Tres de Febrero/Museo Nacional Centro de Arte Reina Sofía, 20I4). 
DOI: http://dx.doi.org/10.22201/iie.18703062e.2018.112.2625

I8

FRANCISCO GELMAN CONSTANTIN

Parir (o no): especie, goce y cuerpos periféricos

Que la intersección de tiempos compromete íntimamente a los cuerpos es principio rector de la poética de Wehbi por lo menos desde que el Periférico de Objetos aborda en 1995 el texto de Heiner Müller "Hamletmaschine". En la obra de Müller se defiende una dialéctica histórica que opone, por una parte, la historia de los hombres — serie indefinida de las calamidades bélicas, la "marcha fúnebre" ${ }^{17}$ como sentido de la linealidad histórica, glorificada en la idea de progreso pero más parecida a la acumulación de ruinas sobre ruinas de "Sobre el concepto de la Historia"- ${ }^{18}$ y, por otra, el cuerpo femenino como soporte de una reavivación cíclica de la vida, el sacrificio ilimitado de nueva progenie para que la sucesión de destrucciones pueda renovarse y el sacrificio de la mujer como mera sede reproductiva. Al pasar de las resonancias benjaminianas a la cita abierta, "Hamletmaschine" escribe las condiciones de esa dialéctica como obra de la propia violencia masculina de la historia de los hombres. Hamlet ironiza sobre el asesinato de su madre como renovación de la virginidad para el matrimonio con Claudio: "Yo haré que de nuevo seas virgen, madre, para que tu rey tenga una boda con sangre. EL SENO MATERNO NO ES CALLE DE SENTIDO ÚNICO [DER MUTTERSCHOSS IST KEINE EINBAHNSTRASSE]". ${ }^{9}$ El cuerpo de la mujer soporta con su recursividad la dirección irrefrenable de la Historia, la Einbahnstraße [calle de sentido único] benjaminiana, ${ }^{20}$ sólo bajo condición del tajo que interpone la espada de Hamlet, que convierte a la mujer en capital biológico, en materia fungible para el destino de la especie.

Sin embargo, "Hamletmaschine" prevé otro modo de diferir de la acumulación de calamidades, posibilidad con la que Hamlet especula desde temprano en el texto al imaginar su propio cambio de sexo: la mujer como condición de una ruptura radical, ya no simple antítesis solidaria de la historia de los

I7. Heiner Müller, Máquina Hamlet. Cuarteto. Medeamaterial, trad. de Gabriela Massuh (Buenos Aires: Losada, 2008), 17.

I8. Walter Benjamin, "Über den Begriff der Geschichte”, en Gesammelte Schriften I (Fráncfort del Meno: Suhrkamp, 199I), 69I-704.

19. Müller, Máquina Hamlet, 20. Revisión de la traducción del alemán a partir de Heiner Müller, "Hamletmaschine", www.peter-matussek.de/Leh/S_32_Material/S_32_M_I3/MUELLER_DIE_HAMLETMASCHINE.pdf, consultado el 7 de febrero de 2016.

20. Walter Benjamin, Dirección única [Einbahnstraße], trads. Juan José del Solar y Mercedes Allende Salazar (Madrid: Alfaguara, 1987). 
hombres. La vía coagula en la amenaza final de Ofelia, que concluye en la cita del clan Manson:

En el nombre de las víctimas. Expulso todo el semen que he recibido. Hago de la leche de mis pechos un veneno mortal. Retiro el mundo que engendré. Ahogo entre mis muslos el mundo que di a luz. Lo entierro en mi sexo. Muerte a la felicidad del sometimiento. Que vivan el odio, el desprecio, la rebeldía, la muerte. Cuando atraviese la alcoba empuñando el cuchillo, sabrán la verdad. ${ }^{21}$

Contra la espada de Hamlet, el cuchillo de Ofelia; ya no dos principios complementarios, sino una diferencia irreductible. El cuerpo de mujer hace saltar la Historia sofocándola en su interior, como recogimiento disidente contra la identificación trágica ("madre") que le propone su época. Es sobre esta tercera vía que se sostiene la Ofelia del Periférico de Objetos cuando la compañía monta Máquina Hamlet. La pieza del Periférico, estrenada en el Teatro Callejón en 1995, cede la totalidad del texto de Müller a una voz en off, y libera a los intérpretes para la actuación gestual y la manipulación de muñecos de escala humana y otros objetos. Al describir la obra ante quienes la documentaron en video, Ana Alvarado se aproxima a la Einbahnstraße de Müller/Benjamin cuando sitúa en Máquina Hamlet la pregunta respecto de "si nosotros podemos interrumpir la cadena de violencia"; García Wehbi responde que esa cadena es irrevocable, en tanto inscrita en la "naturaleza humana". 22

Sin embargo, la expresión "naturaleza humana” y el diagnóstico que de ella depende son menos inocentes de lo que podrían parecer a primera vista. Vale la pena leerlos en conjunto con la reconstrucción de la obra que ofrece el sitio web de García Wehbi — con palabras de Alejandro Tantanián, él mismo integrante más tarde del Periférico- en la fórmula "la destrucción del género humano: única salida posible del laberinto" (las cursivas son mías), ${ }^{23}$ para admitir que acaso la violencia deba situarse en relación estricta con el universal

2I. Müller, Máquina Hamlet, 30.

22. Los testimonios de los integrantes del grupo aquí citados pertenecen al registro fílmico oficial, en el que la entrevista a los artistas precede las imágenes de la obra. La versión transformada a DVD de ese video, así como del conjunto de las piezas escénicas del Periférico de Objetos, proviene del archivo personal de Alvarado, quien generosamente se prestó a esta investigación y aportó precisiones testimoniales suplementarias a su ya de por sí riquísima colección.

23. Alejandro Tantanián, "Un leviatán teatral", Revista Teatro/Celcit, núm. 22 (2002): s.p. 
"Hombre" 24 y por tanto quepa imaginar que algo siga vivo en los cuerpos de esos sujetos luego de la extinción de la especie. Luego del género y la naturaleza humanos, un resto mantiene la herida abierta, viva, donde antes hubo hombres.

La respuesta, como se anticipaba, corre por cuenta de Ofelia. La Ofelia del Periférico, primero muñeco durante el parlamento de Hamlet, es luego encarnada por Alvarado cuando la voz en off se prepara para el monólogo de ella. Se presenta al público presa de una vitrina sin vidrios que instalan en el centro de la escena los hombres-rata, los beneficiarios y ejecutores de la cadena histórica de calamidades. Engalanada de fiesta, con vestido y guantes rojos, con lentes oscuros que fortifican su parsimonia ante el trajín de los hombres-rata, Ofelia espera el momento de hablar, dispuesta sin inquietud para ser mirada. Entre tanto recibe el cigarrillo que le ofrecen y fuma impertérrita mientras el offdespliega su parlamento. Pero el cigarrillo, que pudo complementar su disposición como objeto de exhibición y deseo masculino, prepara de hecho la desobediencia. Con las últimas palabras de su parlamento incendiario, Alvarado aplasta el cigarrillo encendido contra su mano enguantada y lo convierte en prótesis de un goce sanguinario irreductible a cualquier instinto de conservación. Con un mismo paso rechaza el cuerpo salubre de la madre nutricia que provee los campos de guerra y el cuerpo sensual dispuesto al deseo masculino, para retraerse en cambio a un goce no-todo; expropia a los hombres-rata el contenido de su vitrina, tanto del museo de historia natural como del peep show. Es de esa quemazón primera que proviene la incineración final de todo el escenario: el goce femenino sostiene la destrucción de la historia de los hombres, he ahí el añadido decisivo que el Periférico introduce en el texto de Müller y al que acaso se deba anudar el feminismo radical de la obra posterior de García Wehbi.

\section{Retornar: repetición en el cuerpo}

58 indicios sobre el cuerpo, con todo, conduce - al reenviar a El hombre de arena - antes a la autómata enamorada de Ernst Theodor Amadeus Hoffmann que al autómata ajedrecista de "Sobre el concepto de Historia", pero en cualquiera de los dos casos está en juego la derrisión del concepto de progreso, al desarticular cualquier idea inocente de la técnica. Los relatos de Hoffmann deciden en Freud la formulación del concepto de lo ominoso, que otorga acceso

24. Lacan, Les Séminaires, 8342-8347. 
a una temporalidad iterativa, del retorno terrorífico de lo igual; ${ }^{25}$ el tiempo de la repetición es una mancha inquietante en el relato de progreso, allí donde es imposible sostener unívocamente la separación entre el retorno de lo reprimido — en la infancia — y la reafirmación de lo superado — en una historia de las mentalidades iluminista. ${ }^{26}$

Es de hecho porque el "indicio" de una relación a distancia entre 58 indicios y El hombre de arena es suficientemente sutil como para no haber sido calculado, que el cuadrado de tierra seca tiene la intensidad de aquel "factor de la repetición no deliberada [que] vuelve ominoso algo en sí mismo inofensivo". ${ }^{27}$ La compulsión de repetición como prueba del inconsciente supone la crítica del discurso optimista civilizatorio del progreso y por eso no es extraño que el artículo freudiano fuera clave en la transposición que el Periférico de Objetos produjo del cuento de Hoffmann, algunos ańos antes de intervenir sobre la dialéctica histórica de Benjamin y Müller. En su puesta de El hombre de arena en 1992, el grupo se apoyaba en forma declarada en la lectura psicoanalítica del relato fantástico ${ }^{28}$ para situar la persistencia de las formas autoritarias de subordinación más allá del fin de la dictadura y el recomienzo de las elecciones libres, y desnudar la fragilidad de las esperanzas de los primeros ańos de la posdictadura: la violencia se repite más allá del celebrado progreso hacia la democracia. En los cuerpos despedazados de los muñecos se condensa una crueldad que nunca abandona el grado cero, que siempre se reencuentra en el mismo lugar, por medio de las impunidades y las persistencias. En las palabras de Tantanián, de Variaciones sobre B. a El hombre de arena,

la democracia [...] empieza a mostrar su falso rostro, y, en lo intestino de el PERIFÉRICO, se traza el arco que condensa la realidad política. La relación "sujeto-objeto"

25. Sigmund Freud, "Lo ominoso", en Obras completas. XVII, trad. de José Luis Etcheverry (Buenos Aires: Paidós, 1992), 238.

26. Freud, "Lo ominoso", 248. Si, tal como lo veían los surrealistas, el psicoanálisis de Freud puede aparecer a algunos como una última instantánea de la razón iluminista, el racionalismo de hecho no sobrevive intacto a la empresa freudiana. Enfrentado a la pregunta de qué ocurre con "la razón después de Freud", Lacan remite a la instancia de la letra como principio de una nueva racionalidad, montada sobre la compulsión de repetición que rige sobre cualquier sujeto y que por tanto inhabilita una narrativa del progreso; véase Jacques Lacan, "L'instance de la lettre dans l'inconscient, ou la raison depuis Freud", en Écrits I (París: Seuil, 1999), 493 y 493n.

27. Freud, "Lo ominoso", 237.

28. En palabras de Alvarado, en entrevista personal, "El hombre de arena está más influido por el texto Lo siniestro de Freud que por Hoffmann". 
nada tiene que envidiarle a la relación “estado-sociedad” en la Argentina de los '9o. Los “cirujanos-sometedores" y los patéticos ciegos mendigos de EL PERIFÉRICO son sucedáneos del poder político. Radicalizando aún más este discurso llega en 1992 EL HOMBRE DE ARENA. ${ }^{29}$

Cuando el cuadrado de tierra que enmarca 58 indicios renueva la cita de $E l$ hombre de arena, inscribe la posdictadura como condición del performance de 20I4. En lugar de hacer de la posdictadura una hipótesis historiográfica a la manera de Jorge Dubatti, ${ }^{30}$ la repetición compulsiva en la obra de Wehbi la inscribe como gesto mínimo de negatividad frente a cualquier historicismo voluntarista que dictamine algunas décadas o batallas ganadas, ${ }^{31}$ en eco descolocado con aquel anticlimático Heiner Müller que en tiempos de la reunificación alemana deploraba la generalización de la democracia liberal. ${ }^{32}$

El efecto de anacronismo que provoca la presencia del cuadrado de tierra en el interior del performance de 2014 depende del tiempo de las obras mismas, y no debe entenderse como la llegada del tiempo de la represión de la militancia política partidaria al tiempo de la normalización de la disidencia sexual. Con la expresión "perder la forma humana" (tomada del Indio Solari en cita de Castaneda) las investigadoras y los investigadores de Red de Conceptualismos del Sur señalaban ya en los propios años ochenta largos la coexistencia y articulación — no exenta de conflictos — entre los movimientos de disidencia sexual y los de denuncia de las prácticas estatales de tortura, secuestro, asesinato y desaparición; aludamos también a las acciones de la Coordinadora Contra la Represión Pública e Institucional (Correpi) — por nombrar sólo un ejemplo- para dejar ver el modo en que ambos reclamos se conectan hoy mediante la focalización en las instituciones punitivas, se trate de la persecución del colectivo trans, o de la de activistas gremiales o políticos.

29. Tantanián, "Un leviatán teatral”.

30. Jorge Dubatti, "El teatro 1983-2013: Posdictadura (después de la dictadura, consecuencias de la dictadura)", ILCEA, núm. 22 (2015): s. p.

3I. Vale la pena comparar este encuentro con la posdictadura con la búsqueda de la "intemperie" que suscitó a Valeria Flores la confrontación con las prácticas de arte/política de los "años ochenta extendidos'" expuestas en Perder la forma humana, véase Red de Conceptualismos del Sur, dossier "El arte, entre la lucha y la fiesta", Revista CIA, núm. 4 (agosto de 20I5): 74-80.

32. Slavoj Žižek, "Heiner Müller out of joint", consultado el I3 de noviembre de 2015, en www.lacan.com/mueller.htm. 
Con ello, específicamente, en los recorridos genealógicos por la obra del propio Wehbi se advierte cómo las prácticas de montaje manifiestan supervivencias y repeticiones que impiden la parcelación histórica de los reclamos, así como las articulaciones internas concretas de ambas dimensiones en sus intervenciones escénicas. En este sentido, y para ampliar la trayectoria temporal, al modo en que "Máquina Hamlet" conectaba en 1995 el enfrentamiento a la cruenta marcha histórica del capitalismo con el feminismo radical, podría añadirse la ligazón en clave posthumanista de desobediencia sexual y anticapitalismo por medio de la ambivalencia del concepto de "reproducción" (sexual/de las relaciones de producción) en "Hécuba o el gineceo canino" de 20II, o mediante la compra y venta de cuerpos en "El orín come el hierro..." de 2006.33

En su propia reapertura de los tiempos, reacios a los optimismos de Estado, 58 indicios y Communitas - el libro en coautoría con Nora Lezano que sucede al performance 34 articulan reiteradamente la promesa de una democracia radical como porvenir inalcanzado, como disputa sin caducidad.

\section{Incorporar (o no): la lengua y el cuerpo}

Pero 58 indicios se sostiene tanto sobre el montaje de tiempos cuanto sobre el de los cuerpos. En primer lugar porque en el interior de su cultura, como declara Lezano a raíz de Communitas: "Un cuerpo desnudo más que mostrar, afirma". 35 Y en palabras de Wehbi, "La violencia, la memoria, la sexualidad, el deseo o el tiempo pueden ser los tópicos, pero es el cuerpo la forma de enunciarlo" ${ }^{6}$ Para que un cuerpo pueda enunciar algo (el contenido de la afirmación todavía no es

\section{García Wehbi, Botella en un mensaje.}

34. Como destaca Daniela Berlante, Communitas desafía la convicción teórica de que el archivo de una experiencia implique su decepción (véase Daniela Berlante, "Communitas", consultada el I5 de marzo de 20I5, en http://revistaotraparte.com/semanal/teatro/communitas/); antes bien, el ensayo de Lezano y Wehbi está a la altura del performance precisamente porque no lo preserva, sino que lo multiplica y lo transforma. En el desplazamiento a la nueva materialidad, la intervención artístico-política radicaliza algunas de sus posibilidades de insubordinación. La sustitución del artista por el sujeto cualquiera produce un efecto democratizador: no sólo podrá enunciar su cuerpo quien pueda defenderse en escena habilitado como performer, puesto que en el estudio fotográfico no se le exige el dominio de ninguna técnica.

35. Ivana Soto, "Contralectura sobre la belleza", Revista N, suplemento de Clarín, 3 I de enero de $2015,26$.

36. Rosso, "Carne de cañón", 4. 
el asunto) tiene ya siempre que haber entrado en composición con el lenguaje; sólo en el interior de ese montaje, como producto de esa configuración, puede él mismo hablar, incluso si su enunciado fuera a la postre la contestación de la formación simbólica en que se constituyó como cuerpo de un sujeto. Toda vez que distingue al homo sapiens su posesión de "infancia", un tiempo presuposicional en el que careció de habla, ${ }^{37}$ para que su cuerpo afirme esto o aquello, tuvo que configurarse en ese choque entre materia viviente y palabra ${ }^{38}$ que los psicolingüistas llaman conciliatoriamente "adquisición del lenguaje": "[e]l cuerpo adosó al cuerpo el logos". ${ }^{39}$ Es en esa precisa medida, además, que 58 indicios sobre el cuerpo, el performance dirigido por Wehbi, vuelve el ensayo " 58 indicios sobre el cuerpo" que la origina contra la filosofía de su autor, Jean-Luc Nancy.

El texto de Nancy, publicado originalmente en francés en 2004, prolonga y concentra hasta el aforismo las reflexiones que el autor presentaba una década antes en Corpus [fr. 1992], aunque también las empuja hasta las réplicas paradójicas que sirven a García Wehbi para tomar partido contra algunos de sus supuestos. Por lo que interesa a esta investigación, cuando el ensayo de 2004 repudia el concepto de "incorporación" y hace del cuerpo "extenso" e "impenetrable", $4^{\circ}$ lo que está en juego es la disyunción absoluta de cuerpo y lenguaje que defendía el ensayo más temprano. En efecto, Corpus situaba una heterogeneidad insalvable entre la materia viviente envuelta por la piel y la escritura, un "límite absoluto" mediante el cual "nada transita" y en el que sólo obsta un tacto entre infranqueables; Nancy declaraba detestar "la historia kafkiana de La colonia penitenciaria, falsa, fácil y grandilocuente", por implicar "no sé qué marcas que vendrían a inscribirse sobre los cuerpos", "improbables cuerpos que vendrían a trenzarse con las letras" ${ }^{4 \mathrm{II}} \mathrm{El}$ cuerpo contemporáneo, añadía, es extensión, el espaciamiento mismo que lo aparta de la letra. ${ }^{42}$ Aunque el nombre propio que figura es el de Kafka, es patente que aquello impugnado detrás de la hipótesis de la "inscripción sobre los cuerpos" es el Foucault de la

37. Giorgio Agamben, Infancia e historia, trad. de Silvio Mattoni (Buenos Aires: Adriana Hidalgo, 2007), 64-7I.

38. Jacques-Alain Miller, "Lire un symptôme" (conferencia de cierre en el IX Congreso de la New Lacanian School of Psychoanalysis, Londres, 2 y 3 de abril de 20II).

39. Emilio García Wehbi y Nora Lezano, Communitas (Buenos Aires: Planeta, 20I5), I8I.

40. Jean-Luc Nancy, 58 indicios sobre el cuerpo - Extensión del alma, trad. de Daniel Alvaro (Buenos Aires: La Cebra, 2007 [fr. 2004]), 22, I3.

4I. Jean-Luc Nancy, Corpus, trad. de Patricio Bulnes (Madrid: Arena, 2003 [fr. I992]), I4.

42. Nancy, Corpus, I8-2I. 
Historia de la sexualidad $I,{ }^{43}$ así como su inflexión queer en El género en disputa de Judith Butler. ${ }^{44} \mathrm{Si}$ — como ha hecho notar Joan Copjec— $-{ }^{45}$ el foucaultianismo clásico de esos textos suponía la inmanencia absoluta entre el discurso que integra los dispositivos disciplinarios o biopolíticos y la producción de cuerpos, Nancy les oponía la absoluta excripción, separación irreductible que figura en su obra como utopía emancipatoria. En la misma línea, concluía el texto de 2004 postulando dos "esencias" sexuales corporales definidas una por relación con la otra y con prescindencia de la significación. ${ }^{46}$

García Wehbi, por su parte, como anotábamos, había sido ya prevenido - en los ańos noventa, en su tránsito compartido por la dramaturgia de Müller- de los efectos normativos y crueles de la creencia en dos esencias sexuales complementarias, exteriores y separadas respecto de los efectos del lenguaje. Ninguna idea le es más ajena, en su artaudianismo militante, que la de una distancia infranqueable entre cuerpo y lenguaje. El performance de $2014 \mathrm{y}$ el libro de 2015 se invierten en cambio en la imbricación entre uno y otro, que explica las aserciones de Lezano y Wehbi sobre el carácter afirmativo (proposicional y no deíctico) del cuerpo desnudo. En una toma de posición categórica, las y los performers de la pieza, justo después de leer el fragmento del texto de Nancy que le toca a cada uno, al desnudarse todavía parados frente al micrófono, incorporan su cuerpo como último enunciado de su parlamento, y exhiben además los números que llevan dibujados sobre la piel. En el mismo momento en que se vuelven contra la excripción al incorporar un cuerpo en el meollo del habla y una cifra en la superficie de la piel, por otro lado, los y las intérpretes se alejan de cualquier pretensión de inmanencia, precisamente por cuanto rechazan el libreto que pretendía dirigirlos (el ensayo de Nancy). En un movimiento de síncopa característico de la poética de Wehbi, los cuerpos saltan a la vista fuera del lugar que se les reservaba, e inscriben su relación constitutiva con el discurso en la misma medida en que se le enfrentan. Y los textos de Nancy que los performers alteran preparan, sin embargo (hacen lugar a), el ingreso de los cuerpos como un decir.

43. Michel Foucault, Histoire de la sexualité I: la volonté de savoir (París: Gallimard, I976).

44. Judith Butler, Gender Trouble (Nueva York: Routledge, I990).

45. Copjec, Read My Desire.

46. Nancy, 58 indicios, 34 . 
DOI: http://dx.doi.org/10.22201/iie.18703062e.2018.112.2625

26

FRANCISCO GELMAN CONSTANTIN

Montar: la lengua en el cuerpo

Por un desvío paradójico dadas las prevenciones del artista frente al psicoanálisis - por lo menos desde que el Periférico de Objetos montara Zooedipous en 1998 y hasta el recorrido de los textos de Slavoj Žižek en El grado cero del insomnio (Teatro Beckett, 2015)—, ${ }^{47}$ acaso la formulación teórica más acorde que pueda encontrarse para la concepción que sostiene 58 indicios esté en la teoría lacaniana del montaje. La palabra "montaje" comienza a introducirse en los seminarios de Lacan en los años sesenta, haciendo eco de la expresión freudiana de "aparato psíquico", y va adquiriendo presencia conceptual cada vez más definida, que todavía se advierte en los años setenta como parte de la caracterización del discurso como "artefacto". ${ }^{8}$ Aunque también tiene pleno espesor terminológico cuando define al fantasma como "montaje del deseo", 49 la noción de montaje toma precisión conceptual plena como parte de la reformulación del término "pulsión".

Durante su curso de 1964, Les quatre concepts fondamentaux de la psychanalyse, Lacan se detiene sobre la palabra "montaje" y precisa que debe servir para privar a la pulsión del finalismo que pueda proceder de alguna comprensión del funcionamiento de las máquinas o de su reducción a una noción simplista de "instinto"; en cambio, el montaje, pensado en relación con ciertos collages surrealistas — sin duda resuenan allí entre otros las operaciones de su amigo Georges Bataille en Documents y Acéphale—, sugiere entender la pulsión como una composición "sin pies ni cabeza", "la marcha de un dínamo que ramificaría en una toma de gas con una pluma de pavo que sale de alguna parte y que excita el [iojo?] con el vientre de una mujer joven".$^{50}$ La coalescencia con las obras de Wehbi comienza a comprenderse, toda vez que al artista el cuerpo se le aparezca como "el territorio extrańo en donde confluyen lo sofisticado y lo salvaje, bello como el encuentro fortuito de una máquina de coser y un paraguas sobre una mesa de disección", ${ }^{\text {SI }}$ utilizando una cita a Lautréamont que completa la genealogía surrealista.

47. Raquel Tesone, “Al diván: Emilio García Wehbi”, consultado el 26 de febrero de 20i6, en www.revistaelinconsciente.com/2016/o2/26/al-divan-emilio-garcia-wehbi/.

48. Lacan, Les Séminaires, 7732.

49. Jacques Lacan, "Allocution sur les psychoses de l'enfant", Autres Écrits (París: Seuil, 200I), 368.

50. Lacan, Les Séminaires, 5210.

5I. Wehbi y Lezano, Communitas, 178. 
Lo que de la pulsión se debe concebir como "montaje" de acuerdo con Lacan (leído desde Wehbi) es pues el "salto sin transición" entre heterogéneos, ${ }^{52}$ la conjunción entre el viviente y el lenguaje que no resuelve de un plumazo su divergencia como totalidad u organismo. Porque la pulsión es montaje, entonces, composición sin identidad, puede el cuerpo articular una voz sin quedar prendido enteramente por el discurso que se la presta: porque hay montaje es posible la desobediencia. ${ }^{33}$ Es en esta inflexión precisa, entonces, que vale la pena pensar el desafío que 58 indicios levanta, valiéndose del texto de Nancy para transformar su teoría de forma radical, para afectarla de la presencia de cuerpos en su interior (y no en su límite). Y esos cuerpos, rodearlos de las marcas que deciden la dirección precisa de su disidencia. Porque el performance es el montaje de 59 cuerpos y las palabras del ensayo, pero también de unas secuencias coreográficas diseñadas a partir de los movimientos singulares concebidos por los y las performers, y —en la función final de noviembre de 20I4- de un espacio estatal dedicado a la memoria. Si el cuerpo de Nancy es el tener lugar, a los cuerpos de 58 indicios sobre el cuerpo inversamente hay que hacerles lugar; ése es el uso del texto y del cuadrado de tierra, la elaboración de la posición exacta en la que vienen a insertarse los cuerpos: el discurso en el que están montados. Para situar con justeza ese lugar se puede comenzar, invirtiendo la cronología, por las fotografías que integran el libro de Wehbi y Lozano, y bosquejar el espacio de ellas.

\section{Imaginar, enunciar un cuerpo}

Ya sin cuadrado de tierra, el tapiz negro detrás de los cuerpos embarrados en las imágenes de Communitas es sin duda el de un estudio tradicional, la escenografía de la fotografía a demanda del siglo XIX, antes del arte fotográfico y el fotoperiodismo, un servicio pagado por el retratado. Pero la línea de mando no es tan unívoca; Lezano, formada como bióloga, convoca también con

52. Lacan, Les Séminaires, 5210, 6156.

53. Resulta elocuente en este sentido que la propia Butler, en conferencia en la Facultad de Filosofía y Letras de la UBA el I8 de septiembre de 20I5, mientras se consagraba a su lectura del Mal faire, dire vrai de Foucault acabara situando el avowal [asentimiento] de un sujeto a la gestión jurídica de su cuerpo implícitamente muy cerca de la Bejahung [afirmación] freudiana, y — de manera ya explícita—señalara la necesidad, a la hora de teorizar la desobediencia, de una reformulación de las relaciones entre el foucaultianismo y el psicoanálisis. 
el fondo negro el espacio abstracto de la experiencia de laboratorio, donde su mirada científica inventa marcos experimentales en los que dejar fuera algunas variables y quedarse sólo con el meollo. Ese gobierno de la fotógrafa sobre sus modelos sobresale en su propio relato del ejercicio profesional, cuando retrata a celebridades de la música popular:

La gente se impresiona mucho con la muestra [Fan, de 20I5, en el Centro Cultural Recoleta] y algunos, conocidos y desconocidos, me dicen "gracias". A mí me emociona. Pero cuando me hablan de la "impresión” me pregunto qué será. Y pienso: no pueden creer que yo hago lo que quiero con ellos. Que les hago hacer cosas. No pueden creer ese poder. 54

Hacer hacer cosas, ésa es la dimensión de dominio que funda el espacio de la fotografía de estudio en la práctica de Lezano. Respecto del estudio dispuesto para las tomas de Communitas vale la cualidad de espacio de "decisión soberana" tal como lo circunscriben las instalaciones artísticas de acuerdo con Boris Groys; 55 lo mismo puede decirse respecto de la superficie que delimita el cuadrado de tierra durante el performance: espacios de excepción en el pleno sentido agambeniano. No sorprende, entonces, que Ivana Soto haya visto en el performance un "inventario de tipos humanos dentro de un tiempo y un espacio obsesivamente regulados" ${ }^{6}$ Sin embargo, de manera paradójica, bajo las condiciones del marco específico que Wehbi y Lezano producen entre 58 indicios y Communitas, la orden de la fotógrafa y el director soberanos bien puede ser “icuenten, inventen su propia historia!", así como el propósito de las coreógrafas en los performances, Alejandra Ceriani, Alejandra Ferreyra Ortiz y Julieta Ranno, había sido el de precisar y desarrollar los movimientos sugeridos por los mismos y las mismas intérpretes. La autoridad autoral/directoral se agota en la suspensión de las órdenes preexistentes y la cesión del espacio al enunciado que portan los cuerpos.

54. Lezano en Mariana Enríquez, "Te vi”, en "Radar”, sumplemento de Página/I2, 28 de junio de 20I5, suplemento 4 .

55. Boris Groys, Volverse público, trad. de Paola Cortés Rocca (Buenos Aires: Caja Negra, 20I4), 53-67.

56. Soto, "El lugar de las batallas", 30. 


\section{Sobrescribir: los tiempos de un cuerpo ante el Estado}

El entrejuego de textos e imágenes en el libro, y el desarrollo coreográfico del performance recurren a los cuerpos para buscar un libreto. "[S]u imagen opera como un lenguaje en clave que merece ser descifrado"; 57 como ha dicho Gabriela Cabezón Cámara sobre Communitas, recogen "cuerpos que llevan su biografía inscripta", ${ }^{8}$ con la peculiaridad de que — por el modo de montar esos cuerpos- el mensaje que se pretende hacer legible en ellos forzosamente no ha de coincidir con el habla de su época: el cuerpo "tiene sus propias razones, ajenas al mundo pero formando parte de él", 59 en él la biografía puede entrar en disidencia con la Historia. En desafío abierto a aquellas prácticas institucionales que parcelan, por un lado, la memoria de las políticas de exterminio de la última dictadura militar argentina respecto de, por el otro, la precariedad de las condiciones contemporáneas de vida bajo la soberanía dispersa de las biopolíticas de Estado, 58 indicios y Communitas producen su conjunción en la desobediencia de los cuerpos a un gobernar señalado por el cuadrado de tierra como repetición anacrónica de la posdictadura ${ }^{60}$ Las y los performers empapan de goce la tierra fúnebre de El hombre de arena — que no deja por ello de acompañarlos y decidir el umbral de su discurso- para transformarla en el barro que pinta las cicatrices de sus cuerpos contemporáneos.

El tránsito entre la tierra y el barro se consolida en la lógica del montaje: la heterogeneidad se mantiene irreductible, pero cada término es afectado por el acontecer efectivo del vínculo (del salto, de la cita), el "cuerpo-presente" por el "cuerpo-memoria" y viceversa. ${ }^{6 \mathrm{I}}$ En Communitas, la ausencia de la tierra se subsana con más letra:

el cuerpo es siempre resiliente. Siempre. Hasta en los casos más agudos de dolor. Porque la resiliencia no es una forma de adaptación, sino de rebelión. Así, las huellas

57. Wehbi y Lezano, Communitas, I33.

58. Gabriela Cabezón Cámara, "Todo cuerpo es político", en "Soy”, suplemento de Página/I2, I3 de febrero de 20I5, II.

59. Wehbi y Lezano, Communitas, 62.

6o. En este sentido, la última función del performance entraba en resonancia solidaria con su ocasión, la invitación a las V Jornadas de Diversidad y Género, que, ubicadas en el Centro Cultural de la Memoria, se permitían, sin embargo, discutir la penalización del aborto en concomitancia con las prácticas de tortura y desaparición.

6I. Véase Gabo Ferro en García Wehbi y Lezano, Communitas, I2. 
DOI: http://dx.doi.org/10.22201/iie.18703062e.2018.112.2625

de la guerra contra el mundo lo empoderan. La memoria del trauma se imprime en el cuerpo como una marca de agua de su propia identidad, como un fenómeno de veladura que abre puertas a la interrogación. Como la pintura de André Masson que Lacan colocó delante de El origen del mundo de Courbet. ${ }^{62}$

$\mathrm{Al}$ conceptuar casi las experiencias como troumatisme y las memorias como semblantes verdaderos, el texto — que acompaña los retratos de Alejandro Di Franco luciendo su pantorrilla amputada y de Romina Bloise embarazadaintroduce en el núcleo doctrinario del libro algunas de las expresiones clave de los discursos del activismo político en torno a la memoria de las violencias de Estado en Argentina. En el montaje de las fotografías y los textos, el tiempo de los cuerpos se escinde y desplaza, e impide que la imagen paralice la historicidad de esas vidas o que el texto se deseque en historiografía desafectada; Di Franco no es un sobreviviente de la guerra de Malvinas ni Bloise una desaparecida o su feto un futuro Hijo por la Identidad, pero el poder de anacronismo del montaje alimenta ese semblante. Al intervenir sobre los discursos e imágenes que les dan forma, Communitas complejiza el tiempo de esos cuerpos para librarles un enunciado político preciso.

El recorrido de algunas de las obras más recientes de García Wehbi en colaboración con otras y otros artistas, en conjunto con el bosquejo de sus relaciones posibles con una parte de las producciones escénicas del Periférico de Objetos, suscita un pensamiento de las relaciones entre cuerpos, sujetos y tiempos en un diálogo — no exento de asperezas - con algunas de las líneas principales de la teoría contemporánea, bajo condiciones específicas determinadas por las prácticas culturales y políticas dominantes de su tiempo. Situada de ese modo, la noción de "montaje", utilizada de manera dispersa en los manifiestos y declaraciones de Wehbi, puede adquirir perfiles conceptuales precisos para comprender la forma en que la conjunción de cuerpo y lenguaje en su heterogeneidad sirve a la constitución de una disidencia histórica, incompatible con cualquier historicismo ramplón, y afín al uso crítico del anacronismo en la investigación contemporánea. El cuerpo, al interior de procesos colectivos en los que imágenes y palabras le dan forma, aparece a un tiempo como el soporte duracional sobre cuya reproducción se soporta el tránsito de la Historia con sus aristas más terroríficas, y como el lugar preciso en el que se forjan disidencias al sentido de esa Historia. $\mathrm{Al}$ apoyarse en la división interna

62. García Wehbi y Lezano, Communitas, 46-49. 
que el lenguaje introduce en el cuerpo, la obra de Wehbi trafica tiempos desplazados con los que replicar los discursos de mando de la época. Reintroduce las violencias de Estado del último gobierno de facto argentino para ubicar los cuerpos presentes en el tiempo de una cita persistente con la posdictadura. Un feminismo de la diferencia y el activismo en torno a la memoria de la tortura, desaparición y privación de identidad se montan en su heterogeneidad como sitio desincronizado para una política contemporánea del cuerpo, en batalla no caduca contra la crueldad de las biopolíticas estatales, y como programa de una emancipación democrática en busca de nuevos símbolos, imágenes y movimientos. Al hacer lugar al cuerpo performático, el tiempo se reabre y se habita políticamente su fractura. \$ 